\title{
RECENT UPDATE ON ORAL FILMS: A BENCH TO MARKET POTENTIAL
}

\author{
RENUKA R. TIWARI ${ }^{1}$, UMASHANKAR M. S. ${ }^{1 *}$, DAMODHARAN N. ${ }^{1}$
}

${ }^{1}$ Department of Pharmaceutics, SRM College of Pharmacy, SRM Institute of Science and Technology, Tamilnadu, India

Email: umashankarms269@gmail.com

Received: 24 Jul 2018, Revised and Accepted: 04 Sep 2018

\begin{abstract}
Oral films are gaining a lot of attention as a substitute approach to the conventional dosage form. Over the past few years, many of the pharmaceutical scientists throughout the world are focusing their research on oral films, trying to see the sights of oral films as a novel drug delivery system. The oral films are convenient to swallow for geriatric and pediatric patients, are self-administrable, used for systemic and local action and rapid release of a drug, which makes it an excellent system of drug delivery. This review article mainly discusses the manufacturing aspects of films and their characterization, applications and the constraints in the development of oral films along with highlights of market potential.
\end{abstract}

Keywords: Oral films, Formulation, Evaluation, Drawbacks, Market

(C) 2018 The Authors. Published by Innovare Academic Sciences Pvt Ltd. This is an open-access article under the CC BY license (http://creativecommons.org/licenses/by/4.0/) DOI: http://dx.doi.org/10.22159/ijap.2018v10i6.28725

\section{INTRODUCTION}

An oral film as drug delivery is emerging as an advanced alternative to the traditional oral methods of drug administration. Oral film delivery system is a solid dosage form which dissolves in a short span when administered without chewing or drinking water. Oral films containing active drugs are designed for oral administration, allowing the drug to bypass the first pass metabolism in the liver thus enhancing the bioavailability. Upon dissolution, medication enters bloodstream enterically, buccally and sublingually. Making an oral film involves the use of a hydrophilic polymer as a vital ingredient that rapidly dissolves in the buccal cavity thus delivering medication into systemic circulation. This advanced innovation in the formulation was first invented by Richard and Joseph Fuisz, Garry Myers and Robert Yang. They have contributed over 30 patents in this field [1]. The most favoured route of drug administration is oral route due to cost efficiency and ease of administration which lead to high patient compliance for the pediatric and geriatric group, but it is still challenging route due to swallowing difficulty for pediatric and geriatric patients. The development of novel and safer drug delivery such as oral strips, buccal films are the result of patient convenience and compliance-oriented research. In recent times, an oral film drug delivery system has gained lots of popularity and acceptance [1, 2].

Oral film technology was first invented in the late 1970s just to overcome swallowing difficulties related to tablets and capsules faced by geriatric and pediatric patients but now is trending in pharma industry due to less fragility than other oral dosage forms, dosage accuracy, rapid release, ease of administration. These oral films are also known as oral strips, buccal strips or films. A variety of bioadhesive mucosal dosage form has been developed such as adhesive tablets, gels, ointments, patches and currently polymeric film for buccal delivery is known as mouth dissolving films. Oral films have a shelf life of 2-3 y depending upon the active pharmaceutical ingredient but are unusually sensitive to environmental moisture [3].

The following review was focused on elaborating the manufacturing aspects of films and their characterization, market potential, applications and the constraints in development of oral films. Review and research article on oral films and its market potential that are available in journal databases such as Science Direct, PubMed, Springer, Pharmatutor from the year 2000-2017 were studied and indepth knowledge of oral films in present market was produced. Very few articles before the year 2000 were also considered.

Keywords used to search: formulation, methods of preparation, market potential, patented oral films.
An ideal oral film possesses following properties such as high stability, transportability, ease of handling and administration, no water necessary for application and pleasant taste. Therefore, they are very suitable for pediatric and geriatric patients, bedridden patients; or patients suffering from dysphagia, Parkinson's disease, mucositis or vomiting. Oral films were first introduced to the market as breath fresheners and personal care products such as dental care strips and soap strips. These oral dosage forms were introduced in the United States and European pharmaceutical markets for therapeutic benefits. The first oral strip was developed by Pfizer named as Listerine pocket packs which were used as mouth freshener [1].

\section{Advantages}

- Pleasing and fresh mouthfeel.

- No risk of choking.

- Easy application-no swallowing and chewing difficulties.

- To avoid first pass metabolism.

- Administering of an accurate dose is possible.

- For improved patient compliance, small size is available.

- Rapid onset of action.

- It helps in enhancing stability [4].

- It masks the bitter taste.

- Available in various sizes and shapes.

- Reduce gastrointestinal irritation.

Disadvantages

- Sometimes show the fragile and granular property.

- Hygroscopic in nature thus must be stored in a dry place.

- Require special packaging for the product stability and safety.

- The high dose cannot be incorporated into an oral film.

- $\quad$ Eating and drinking may be restricted.

- Drug unstable at buccal pH cannot be administered.

- A drug with nauseous odour cannot be administered [5] 
Table 1: Comparison between oral films and oral tablets

\begin{tabular}{ll}
\hline Oral films & Oral tablets \\
\hline Oral films have greater dissolution due to large surface area & Oral tablets have lesser dissolution area as compared to oral films \\
They have better longevity than oral tablets & They have less longevity than oral films \\
They have more patient compliance than oral tablets & They have less patient compliance as compared to oral film \\
There is no risk of choking & There can be the risk of choking \\
In oral films, an only low dose can be incorporated & In oral tablets, the high dose can be incorporated \\
\hline
\end{tabular}

\section{Comparison between oral films and oral tablets}

\section{Classification of oral films}

There are three different subtypes of oral films-

1. Mucoadhesive sustained release wafer
2. Mucoadhesive melt away wafer

3. Flash release

\section{Formulation of oral films}

The typical composition of oral films comprises of:

Table 2: Classification of oral films [8-10]

\begin{tabular}{|c|c|c|c|c|}
\hline Subtypes & $\begin{array}{l}\text { Mucoadhesive sustained } \\
\text { release wafer }\end{array}$ & Flash release & Mucoadhesive melt away wafer & Reference \\
\hline Thickness $(\mu \mathrm{m})$ & $50-250$ & $7-20$ & $50-500$ & \\
\hline Area (sq. cm) & $2-4$ & $2-8$ & $2-7$ & \\
\hline Drug phase & Suspension and $\backslash$ or solid solution & Solid solution & $\begin{array}{l}\text { The solid solution or suspending } \\
\text { drug particles }\end{array}$ & 8 \\
\hline Structure & Multilayer system & Single layer system & A single layer or multilayer system & \\
\hline The site of action & Local or systemic & Local or systemic & Local or systemic & \\
\hline Excipients & Low/non-soluble polymers & $\begin{array}{l}\text { Soluble, highly hydrophilic } \\
\text { polymers }\end{array}$ & Soluble, highly hydrophilic polymers & 9 \\
\hline Dissolution & Maximum 8-10 h. & $\begin{array}{l}\text { Minimum } 60 \mathrm{sec} . \\
\text { Maximum 8-10 h. }\end{array}$ & $\begin{array}{l}\text { Disintegrate in a few mins, forming } \\
\text { the gel }\end{array}$ & \\
\hline Application & $\begin{array}{l}\text { The gingival and another region } \\
\text { in an oral cavity }\end{array}$ & Tongue (upper palate) & Gingival or buccal region & 10 \\
\hline
\end{tabular}

Table 3: Composition of an oral film

\begin{tabular}{ll}
\hline Constituents & Quantity \\
\hline Drug & $5 \%-30 \% \mathrm{w} / \mathrm{w}$ \\
Polymer & $45 \% \mathrm{w} / \mathrm{w}$ \\
Plasticizers & $1 \%-20 \% \mathrm{w} / \mathrm{w}$ \\
Saliva stimulating agent & $2 \%-6 \% \mathrm{w} / \mathrm{w}$ \\
Surfactants & q. s. \\
Colouring agent & q. s. \\
Sweetening agent & $3 \%-6 \% \mathrm{w} / \mathrm{w}$ \\
Flavoring agent & q. s. \\
Other agents & q. s. \\
\hline
\end{tabular}

\section{Components of oral film}

\section{Active pharmaceutical ingredient}

The variety of active pharmaceutical ingredients can be administered. Since there is a limitation for the size of the dosage form, high dose drugs are difficult to incorporate into the film. For oral films, ideal active pharmaceutical ingredient (API) preferred should be less bitter, potent and highly lipophilic. The medication incorporated into the film is about $5 \% \mathrm{w} / \mathrm{w}$ to $30 \% \mathrm{w} / \mathrm{w}$ of the dry film, and for multivitamin up, to $10 \%$ $\mathrm{w} / \mathrm{w}$ of the dry film can be incorporated [14].

The ideal characteristics of an Active Pharmaceutical Ingredient are:

- Drug to be incorporated should have low dose up to $40 \mathrm{mg}$

- Drugs with smaller and moderate molecular weight are preferred

- The drug should be stable and soluble in water and saliva

- The drug should be partially unionized at pH of the oral cavity

- A drug should be able to permeate through the oral mucosa.

Special classes of active pharmaceutical ingredient (API) that can be administered are local anesthetics, anti-migraine drugs, and drugs for a sore throat, multivitamins, and melatonin. Other types of drugs are antiallergic, antihistaminic, analgesic, smoking cessations, bronchodilators, nootropic agents, etc [15].

\section{Film forming polymers}

The varieties of polymers are accessible for a formulation of oral films. One of the most critical and essential factors for the selection of polymer to formulate oral film is that it should disintegrate in seconds. The polymers improve the flexibility, hydrophilicity, mouthfeel, and solubility of the oral film. The amount of polymer present in the formulation decides the stiffness and robustness of the film. The amount of polymers used alone or in combination is about $45 \% \mathrm{w} / \mathrm{w}$. The polymers used for formulating oral films should be water soluble, low molecular weight and an excellent film forming capacity. The water-soluble polymers are used as they provide rapid disintegration, good mouth feels and excellent mechanical strength to film. The water-soluble polymers used are pullulan, gelatin, guar gum, xanthan gum, modified starch, PVA, HPMC PVP K30, etc [16].

Out of these polymers, HPMC and Pullulan are the commonly used polymers for the formulation of oral films. HPMC is the propylene glycol ether of methylcellulose. In preparation of the oral film, low viscosity grades of HPMC such as HPMC E3/E5/E6/E15 are used. Pullulan is a neutral glucan (like amylose, dextran, and cellulose) 
with a chemical structure depending on the carbon source, producing microorganism (different strains of Aureobasidiumpullulans) and fermentation conditions [17].

\section{Plasticizers}

A plasticizer is a crucial ingredient of the oral film. The choice of plasticizer depends upon its compatibility with the polymer and the type of solvent used in the casting of the film. It reduces the brittleness of the film and improves the flexibility of the film. It enhances the film properties by lowering the glass transition temperature of the polymer. It lowers the glass transition temperature of the polymer to 40-60 degree Celsius for the nonaqueous solvent system and below 75 degree Celsius for the aqueous solvent system [18]. They should be volatile in nature. The concentration of plasticizer used is $1 \% \mathrm{w} / \mathrm{w}$ to $20 \% \mathrm{w} / \mathrm{w}$ of dry polymer. Plasticizers enhance mechanical properties such as tensile strength and elongation to the film by dropping the glass transition temperature of the polymer. It also reduces the brittleness of the film by setting itself between the polymer chains acting as a hinge to the support thus improving the flexibility of the film. The commonly utilized plasticizers are phthalate derivatives like diethyl, methyl, and dibutyl phthalate, cellulosic hydrophilic polymers plasticized with $\mathrm{OH}$ containing PEG, propylene glycol, polyol, less cellulosic hydrophilic polymers plasticized with esters of citric acid, phthalic acid, diethyl glycol and glycerol [18]. The phthalates are not used currently in the formulation as it shows carcinogenicity. Inaccurate utilization of plasticizer may cause blooming, crack, peeling and split of films [19].

\section{Saliva stimulating agents}

Saliva stimulating agents are utilized to boost the rate of saliva production which aids in a faster disintegration of the oral film formulations. The formulations may contain acids which are used as salivary stimulants. Citric acid, malic acid, lactic acid, ascorbic acid, lactic acid and tartaric acid [9]. Citric acid is the most preferred among them. Sometimes sweeteners are also used as salivary stimulants. The concentration of saliva stimulating agents used is $2 \% \mathrm{w} / \mathrm{w}$ to $6 \% \mathrm{w} / \mathrm{w}$. They can be used alone or in combination [20].

\section{Sweetening agents}

Sweeteners have become the essential part of the food products and pharmaceutical products intended to be disintegrated or dissolved in the oral cavity [21]. They are used in the concentration of $3 \% \mathrm{w} / \mathrm{w}$ to $6 \% \mathrm{w} / \mathrm{w}$. Natural and artificial sweeteners are used to improve the palatability of the oral film formulations. Some suitable sweeteners include-

- Water-soluble natural sweetener: xylose, ribose, sucrose, maltose, fructose, stevioside etc.

- Water-soluble artificial sweetener: sodium or calcium saccharin salts, acesulfame-k salts, cyclamate etc.

- Dipeptide based sweetener: aspartame

- Protein-based sweetener: thaumatin I and II

- Polyhydric alcohols: sorbitol, mannitol, isomalt, maltitol

Polyhydric alcohols, if used in combination, provide good mouthfeel and cooling sensation. Fructose is sweeter than sorbitol and mannitol thus commonly used as a sweetener. Neotame and alitame are 2000-8000 times sweeter than sucrose [22].

\section{Cooling agents}

Cooling agents are added to boost the flavour and to improve the fresh mouthfeel the effect of the oral film. Some cooling agents are WS23, WS3, and Utracoll II which are used with a blend of flavours [13].

\section{Flavouring agents}

Flavouring agents are used to mask the bitter taste of drug and to add some zest to the formulation. The choice of the flavours varies from person to person depending on the ethnicity and taste [9]. Flavouring agents can be acquired from oleoresins extract, synthetic flavour oils derived from different parts of the plant like leaves, fruits and flowers. The amount of flavor needed to mask the taste of medication depends on the flavour type and strength. Flavouring agents utilized are peppermint, cinnamon, nutmeg, vanilla, cocoa, chocolate, coffee, citrus, apple, etc [13].

\section{Colouring agent}

Colouring agents are utilized to impart colour to the formulation to make it eye pleasing. Pigments like titanium dioxide or food, drug and cosmetic (FD and C) act approved colouring agents are incorporated in an oral film when some of the formulation ingredients or drugs are present in suspension or insoluble form. The concentration of the colouring agents should not exceed the level of $1 \% \mathrm{w} / \mathrm{w}$ [13].

\section{Surfactants}

Surfactants are utilized as solubilizing or wetting or dispersing agents which are used to dissolve the film within seconds and to release medication instantly. They are also used to improve the solubility of poorly soluble drugs in oral films. Surfactants used are poloxamer 407, benzalkonium chloride, benzethonium chloride, tweens, spans and sodium lauryl sulphate [23].

\section{Stabilizing and thickening agent}

These agents are engaged in improving the viscosity and consistency of dispersion or solution of film preparation before casting. Natural gums like xanthan gum, carrageenan, locust bean gum and cellulosic derivatives are used [23].

\section{Methods of preparation}

The oral films are manufactured by various approaches.

One or in combination following techniques can be used for the preparation of oral films.

\section{Solvent casting method}

It is the pharmaceutical technique in which active pharmaceutical ingredient is dissolved or suspended in the solution of polymers, plasticizers and other different components dissolved in a volatile solvent like ethanol or water. This material is stated as the film dope which is spread out using established solvent-cast film technique on a constant movement of release media like plastic impregnated paper [19]. Initially, polymers soluble in water are dissolved in water at 60 degree celsius, and all different excipients like shading agents, sweetening agent and flavoring agents are added independently and later included by mixing at $1000 \mathrm{rpm}$. The solution is fused with the active pharmaceutical ingredient, and the entangled air is evacuated and cast as the film. Solvent casting is the best technique for manufacturing films containing heat delicate active pharmaceutical ingredient because the temperature required to expel the solvents is generally low contrasted with those needed for the hot melt extrusion process [24].

\section{Semisolid casting method}

In semisolid casting strategy initially, the solution of water-soluble film-forming polymer is prepared. The obtained mixture is added to a solution of insoluble acid polymer (like cellulose acetate phthalate, cellulose acetate butyrate) which was set up in ammonium or sodium hydroxide [12]. To obtain a gel mass, the appropriate amount of plasticizer is added. Finally, utilizing heat controlled drums, the gel mass is cast into films or ribbons. The thickness of the film is maintained around 0.015-0.05 inches. The proportion of the insoluble acid polymer to film forming ought to be 1:4 [22].

\section{Hot melt extrusion}

Hot melt extrusion is commonly employed to prepare sustainedrelease tablets, granules, and transmucosal and transdermal drug delivery systems. In this technique, the solid mass is formed by blending the drug and other components [24]. The dried granular solid is introduced in the extruder and extrudate obtained is then pressed into the calendar to get a film. The ejected film is then cooled, cut and packed. 
The principle drawback of hot melt extrusion (HME) is that it exposes the film ingredients to high temperature which causes thermal degradation. All the components that are utilized hot melt film must be deprived of water or any other volatile solvents. The heat used for the process can cause such contaminants to boil and create voids in the film, influencing its consistency, quality, strength and appearance [25].

\section{Solid dispersion technique}

The word solid dispersion alludes to the dispersion of one or more active pharmaceutical ingredients in an inert carrier, in a solid state, in the presence of amorphous hydrophilic polymers using techniques like hot melt extrusion. In this technique, immiscible components are expelled with the drug, and then solid dispersions are prepared. Then with the aid of dies, the solid dispersions are cast into films $[12,24]$.

\section{Rolling method}

In this technique, a film-forming solution or suspension containing medication is rolled on a carrier. The solvent is used mostly water or mixture of alcohol and water. The film formed is dried up on rollers and cut into desired shapes and sizes. This is the natural and costeffective technique for the manufacturing of oral films $[12,26]$.

\section{Evaluation of oral films}

The various evaluation parameters for an oral film are as follows:

\section{Dryness/tack test}

There are about eight stages of film drying process. They are set-totouch, dust free, tack-free (surface dry), dry-to-touch, dry-hard, drythrough (dry-to-handle), dry-to-recoat and dry print-free. These tests are primarily used to paint films, but most of the studies can be revised to evaluate pharmaceutical oral films. Tack is the firmness with which the film adheres to an adjunct (a piece of paper) that has been pressed into contact with the film. Various instruments are accessible for this investigation $[4,25]$.

\section{Thickness}

The thickness of the film is related explicitly with drug content and uniformity thus it is essential to determine uniformity in the thickness of the film. Thickness can be estimated by micrometer screw gauge or calibrated digital Vernier calliper at various strategic locations $[16,25]$.

\section{Percent elongation}

When stress is applied to a sample, it stretches, and this is referred to as strain. A strain is the deformation of the film divided by an original dimension of the film. Usually, elongation of the film increases as the plasticizer content increases [27].

$\%$ Elongation = Increase in length/original length $* 100$

\section{Young's modulus}

Young's modulus or elastic modulus is the measure of rigidity or toughness of film. It is given as the ratio of applied stress over strain in the region of elastic deformation as follows:

Young's Modulus $=$ force at corresponding strain/cross-sectional area* $1 /$ corresponding strain

\section{Tensile strength}

Tensile strength is the maximum stress applied to a point at which the oral film sample breaks. It is calculated as the applied load at breach divided by the cross-sectional area of the film as given in the equation below:

Tensile strength $=$ load at breakage $/$ film thickness $*$ film width

\section{Folding endurance}

Folding endurance is determined by repeated folding of the film at the same place till the film breaks. The number of times the film is folded without breaking is recorded as the folding endurance value [25].

\section{Tear resistance}

Tear resistance of the film is a complex function of its resistance to rupture. The primarily minimum rate of loading $51 \mathrm{~mm}(2 \mathrm{in})$ per minute is employed and is designed to measure the force to initiate tearing. The maximum stress or strength enquired to break the sample is reported as the tear resistance value in Newtons (or pound-force).

\section{Swelling property}

Swelling property is studied by using simulated saliva solution. Each film specimen is weighed and placed in a preweighed stainless steel wire mesh. The mesh containing film specimen is immersed into 15 $\mathrm{ml}$ simulated saliva solution in a container. Increase in the weight of the film is observed at the preset interval until a constant weight is observed [25].

The degree of swelling was calculated using;

$\alpha=$ wt-wo/wo

Where wt is the weight of film at a time

$t$ and wo is the weight of film at time zero

\section{Surface $\mathrm{pH}$ of the film}

Surface $\mathrm{pH}$ of the film is measured by placing the film on the surface of $1.5 \% \mathrm{w} / \mathrm{v}$ agar gel followed by putting $\mathrm{pH}$ paper ( $\mathrm{pH}$ range $1-11$ ) on the film. The change of the colour of $\mathrm{pH}$ paper was observed and recorded.

\section{Organoleptic evaluation}

For organoleptic assessment of the product, different controlled human taste panels are utilized. In vitro methods of using taste sensors, especially designed apparatus and drug release assessed by modified pharmacopoeial methods. These in vitro taste assessment apparatus and techniques are well suited for high-throughput taste screening of oral pharmaceutical products [27].

\section{Transparency}

The transparency of the film can be determined using a simple UV spectrophotometer. Cut the film specimen into a rectangle and placed on the internal side of the spectrophotometer cell. The transmittance of the film is determined at $600 \mathrm{~nm}$. The transparency of the film is calculated as follows:

Transparency $=(\log \mathrm{T} 600) / \mathrm{b}=-€ \mathrm{c}$

Where $\mathrm{T} 600$ is transmittance at $600 \mathrm{~nm}$

$\mathrm{b}$ is the film thickness

$\mathrm{c}$ is concentration

\section{Assay/content uniformity}

Assay or content uniformity is determined by any standard assay method described for the active pharmaceutical ingredient in any of the standard pharmacopeia. Content consistency is determined by estimating the active pharmaceutical content in an individual film of content uniformity is $85-115 \%$.

\section{Moisture content}

The amount of moisture in the film is significant as it influences mechanical strength, adhesive properties and friability of the film. Various parameters are liable for elevating water levels such as hygroscopic properties of an active pharmaceutical ingredient, polymers and solvent system used to solubilize the polymeric mixture, and manufacturing methods. The moisture content of the film is measured by several techniques such as Karl Fischer titration or by weighing way [27].

Moisture content $=$ [Initial weight-Final dried weight/Initial weight $]$ $* 100$

\section{Disintegration time}

The disintegration of oral films requires USP disintegration apparatus. The disintegration time limit of 30 seconds or less for 
orally disintegrating tablets described in the Center for Drug Evaluation and Research (CDER) guidance can be applied to oral films. Disintegration time will vary depending on the formulation but typically the disintegration range from 5 to 30 seconds. There is no official guidance available for the disintegration of oral films.

\section{Dissolution test}

Dissolution test can be performed by using the standard basket or paddle apparatus described in any of the pharmacopeias. The dissolution medium mimicking saliva will be selected as per the sink conditions and highest dose of the active pharmaceutical ingredient. At times the dissolution test can be difficult due to a tendency of the oral film to float onto the dissolution medium when the paddle is moving. During the study, the condition of the medium is maintained at $37 \pm 0.5$ degree Celsius and revolution per minute (rpm) at 50 [28].

\section{Applications of the oral films}

- Oral administration of a drug by sublingual, buccal and mucosal route with the aid of oral films have become a preferential delivery approach for treatment requiring speedy drug absorption which includes the ones listed to manipulate pain, allergic reactions, sleep, and nervous system disorders.

- Topical applications: The utilization of oral films can be feasible in the delivery of an active pharmaceutical ingredient which includes analgesic and antimicrobial agents required in the wound healing and other applications [1].

- Diagnostic devices: Soluble films can be loaded with a chemical reagent to permit managed release when exposed to a biological fluid or to form isolation barricades for setting apart reagents to modify a time reaction at intervals within a diagnostic device.

- Vaginal drug delivery system: Films which are meant for vaginal administration can be applied physically without untidiness or inconvenience of gel or cream application. On contact with the vaginal fluid, the film forming substances hydrates to form the hydrogel that functions as the usual vaginal product.

- Gastro retentive drug delivery system: Soluble films are taken into consideration as a dosage form for water-soluble and poorly soluble molecules of various molecular weight in film forming solution. Dissolution of the film caused by $\mathrm{pH}$ or enzyme secretion of the gastrointestinal tract and it is potentially utilized for treatment of the gastrointestinal disorder [13].

\section{Drawbacks in the advancement of oral films}

Technology catalyst gives an idea of the arcade of oral film products which is valued at $\$ 500$ million in 2007 and expected to reach $\$ 2$ billion in future [13]. Recently, oral films are the substitute to tablets and capsules in the market due to patient's preference. Oral films continue to be within commencement stages and can be the prime preference of patient in the future. Though various oral films brands are present, the market remained limited when compared to the oral tablets. Over the counter drugs for pain management and motion sickness have been commercialized in the United States market. Currently, oral prescription films are approved in three major countries which are United States, Japan, and European countries. It gives the impression that worth of oral film market will grow significantly.

Presently, vast literature is accessible on the formulation, development, and evaluation of oral films but formulator faces various difficulties while formulating such dosage forms. Thus it is important to discuss such drawbacks which may facilitate in the future in the formulation and development of oral films. As these drawbacks are directly related to patient compliance, they are given preference in formulation and development [29].

Some of the drawbacks of the advancement of oral films include:

- Insolubility of drug.

- Taste masking of the bitter and nauseous drug.

- High dose incorporation in the film.
- Ample time required for drying of the film.

- Stability of film against temperature and humidity [29].

- Co-administration of drugs.

- Uniformity of dose.

- Special packaging needed.

\section{Insolubility of drug}

The rate-limiting factor to urge to the desired concentration of medication of orally administered formulation in systemic circulation is solubility. Solubility problem is the major challenge for the formulation of oral film of BCS class II drugs which have low solubility and high permeability.

\section{Taste masking of bitter and nauseous drug}

Taste masking is obligatory for bitter drugs used in oral films to improve patient compliance, especially for the pediatric and geriatric group. Taste is the essential factor to be considered in oral films as it is directly applied in the buccal cavity and it needs to remain intact with oral membrane until it gets soluble with saliva in the oral cavity.

\section{High dose incorporation in the film}

In oral films, a high dose can be incorporated assuming that the area of the surface is increased. An area should be increased by maintaining a thickness of formulation. Thus it also increases the volume of the solution required for formulation as the high dose is incorporated due to which it takes more time to get dried.

\section{Ample time required for drying of a film}

The time required for drying plays a crucial role in oral film formulation and also in the rate of production of films in industries. For oral films of thermosensitive drugs hot air oven cannot be used for drying thus, they have to be dried at room temperature. This process is time-consuming and at times may cause various contamination problems also.

\section{Stability of thin film against temperature and humidity}

Oral films consist of about $45 \%$ of polymer which is hydrophilic in nature. In humid conditions film will absorb moisture and gets softened due to the dissolution of a film in water. Amorphous drugs have higher dissolution rates than crystalline forms but lack of physical stability during storage. The best method to prevent the drug from crystallization is to add crystallizing inhibitors like hydrophilic polymers to the amorphous drugs.

\section{Co-administration of drugs}

In oral films utilizing more than one drug, i.e. co-administration of drugs is a challenging task. It affects the disintegration and dissolution time. Co-administration of the drug may also create problems like incompatibility, stability etc.

\section{Uniformity of dose}

Oral films which are meant for administration had to be cut into the desired shape, area and required a dose of medication. To get the uniformity of dose, it is important to cut into the desired area. This is a difficult task in the production and evaluation of oral films.

\section{The special packaging needed}

It is a crucial job to select the packaging material in the pharmaceutical industry to maintain the integrity of the product. There are various packaging options available for the oral films. Most commonly used packaging material is an aluminum pouch. Other materials used are polyester or suitable paper backed packaging or cassette packaging. These packaging cause storage and stability issues during the usage of the product.

\section{Market potential}

The understanding of the market potential of oral films is essential with an industrial point of view to ensure its future growth. As per the 
market projection study for 2015-2025, owns a good perspective of growth as an upcoming technology of drug delivery. Ten oral films are in the market, and twenty-nine are in the stage of various clinical and preclinical trails out of which six products were launched in 2016. Around to proprietary technologies like Pharm Film, Rapid Film, BioFX, etc. are coming up which has $38 \%$ market. Thus it is a potential ground for research and idea of the demand for drug products as oral films is expected to be worth US\$15,984.3 million by the end of 2024 . The worldwide market is estimated to exhibit a compound annual growth rate (CAGR) of $9.0 \%$ with a significant increase of compound annual growth rate (CAGR) of $18.3 \%$ between 2016-2024. North America is having a leading market share of $85.3 \%$.

Targeting of drugs is yet to be covered under this technology. The oral prescription films currently available in the market are 10 . About 29 films are in preclinical and clinical developmental stages. About $54 \%$ of products are oral transmucosal films. By sublingual, buccal or oral mucosal route these films can be administered, providing an advantage of rapid onset of action. Some of these products (approx. 38\%) depend on MonoSol's PharmFilm innovation or Applied Pharma research/labtec Rapid Film innovation. In count to these two, there are over ten other proprietary oral thin film technologies, some of these are currently being utilized for formulating over-the-counter products. The trending OTC drug products are Gas X and Listerine breath freshener. Some of the new businesses like Cynapsus Therapeutics and FFT Medicals have currently developed, and these new upcoming establishments with their oral transmucosal film products are probably going to foster more advancement in the coming couple of years. Of all the showcased products, Suboxone film has obtained acceptance in a short period; other products such as Breakyl, Onsolis, and Zuplenz are also progressing in various topographies. Even India is concentrating on film technology due to which within a short span new companies have emerged such as
Aavishkar Pvt. Ltd and NU therapeutics in Hyderabad while ZYM laboratories in Nagpur.

The extensive literature survey is mostly based on patents of various oral films from multiple patents bodies across the world such as the United States Patent and Trademark Office (USPTO), World Intellectual Property Right Organization (WIPO), European patent office (EPO) and Indian Patent Office (IPO) [18]. The maximum patent filling was found in the United States Patent and Trademark Office (USPTO) of drugs such as sildenafil citrate, dextromethorphan, acetaminophen, buprenorphine and naloxone. India has also established in the market for oral films as pharmaceutical companies such as MonoSol Rx, Warner-Lambert and Lts Lohmann have filed patents in Indian Patent Office (IPO). The key players in the oral film market are MonoSol Rx, Applied pharma research/labtec, Pfizer, Novartis AG, Wolters Kluwer, Solvay and Allergen [30, 31].

There are still various oral films under development such as Montelukast which is used for the treatment of asthma and allergy, and Rizatriptan which is used for the treatment of migraine is developed as a film by MonoSol Rx. Moreover, MonoSol Rx is formulating a testosterone film based therapeutic for the treatment of male hypogonadism and the product is present in Phase-I. Also, Midatech, organization expertise is nanotechnology is joining hands with MonoSol Rx to formulate film-based insulin. (Sach Associates, $5^{\text {th }}$ annual European Life Science CEP Forum for partnering and Investing, March 6-7, 2012, Zurich, Switzerland,). Undergraduate biomedical engineering students of Johns Hopkins University have formulated a new oral film used as breath revitalizer. Bound with the antibody against Rotavirus the strips can be utilized to give the immunization to infants or newborn children in ruined areas [32]. Thus it can be concluded that there is an exponential increase in research in the field of oral films which will substantially influence the pharmaceutical market in the future.

\section{Some patented oral films}

Table 4: Some patented oral films

\begin{tabular}{|c|c|c|c|c|}
\hline Country & Patent number & Title & Inventors & Reference \\
\hline US & 20110305768A1 & $\begin{array}{l}\text { Quick dissolving oral thin film for } \\
\text { targeted delivery of therapeutic agents }\end{array}$ & Hai-Quan Mao et al. & \\
\hline WO & $2012103464 \mathrm{~A} 2$ & Oral thin film vaccine preparation & Brian Pulliam & \\
\hline US & 5948430 & $\begin{array}{l}\text { Water-soluble film for oral } \\
\text { administration with instant wettability }\end{array}$ & Zerbe et al. & 5 \\
\hline WO & $2013085224 \mathrm{~A} 1$ & $\begin{array}{l}\text { Bitter taste masked oral thin film } \\
\text { formulation of Sildenafil citrate }\end{array}$ & Dae-Kun Song et al. & \\
\hline EP & $1680079 \mathrm{~A} 2$ & $\begin{array}{l}\text { Rapidly disintegrating films for delivery } \\
\text { of pharmaceutical and cosmetic agents }\end{array}$ & Scott D Bamhart et al. & \\
\hline EP & 2509631A4 & $\begin{array}{l}\text { pH-sensitive compounds in taste } \\
\text { masking within oral thin films strips }\end{array}$ & A Mark Schobel et al. & \\
\hline WO & 2012053006 A 2 & $\begin{array}{l}\text { Improved oral fast dissolving films } \\
\text { comprising a combination of polymers } \\
\text { and method of preparation thereof }\end{array}$ & Rajesh Jain et al. & \\
\hline US & 6596298B2 & Fast dissolving orally consumable films & $\begin{array}{l}\text { Sau-Hung Spence Leung } \\
\text { et al. }\end{array}$ & \\
\hline WO & $2014183054 \mathrm{~A} 1$ & $\begin{array}{l}\text { The thin film with a high load of active } \\
\text { ingredient }\end{array}$ & Eric Allen et al. & \\
\hline US & 7579019B2 & $\begin{array}{l}\text { Pharmaceutical carrier device suitable } \\
\text { for the delivery of pharmaceutical } \\
\text { compounds to the mucosal surface }\end{array}$ & Tapolsky et al. & \\
\hline US & 6159498 & $\begin{array}{l}\text { Bioerodable film for delivery of } \\
\text { pharmaceutical compounds of the } \\
\text { mucosal surface }\end{array}$ & Tapolsky et al. & \\
\hline US & 6824829B2 & Process for manufacturing thin film strip & Berry et al. & \\
\hline US & 7132113B2 & Flavoured film & Zerbe et al. & \\
\hline US & 7182964B2 & $\begin{array}{l}\text { Dissolving thin film xanthone } \\
\text { supplement }\end{array}$ & Kupper et al. & \\
\hline US & 7241411B2 & Thin film strip & Berry et al. & \\
\hline US & 7267718B2 & Pullulan film composition & Scott et al. & \\
\hline US & 7347985B2 & $\begin{array}{l}\text { Breath freshening and oral cleansing } \\
\text { product with a magnolia bark extract }\end{array}$ & Maxwell et al. & 21 \\
\hline US & 1648712B2 & $\begin{array}{l}\text { A fast dissolving orally consumable film } \\
\text { containing taste masking agent }\end{array}$ & Bess et al. & 33 \\
\hline
\end{tabular}




\section{CONCLUSION}

Oral films have currently gained a lot of consideration as a nonobstructive route of drug delivery. Although most of the formulations today are oral disintegrating tablets, oral films are found more attractive due to easy portability, enhanced patient compliance and simple administration. Apart from using them as medicament films, they can also be used as refreshing mouth films, nutritional supplements, etc. They own many advantages over conventional dosage form. Oral drug delivery system is getting sophisticated day by day to provide better compliance and efficiency in which oral films are capturing a market and challenging pharmaceutical companies for developing oral films for a wide range of drugs. The key aspects for worldwide oral film market are up surging demand of oral films, significant research, and development in the segment, low advancement cost when contrasted with new medications and strategic coalitions with novel innovation proprietors and pharmaceutical titans. This unique technology is found to be flourishing up in the Indian market as well as international market with billion dollar market profiting with the equal emergence in pharmaceutical, food and confectionery sectors. Promising drug delivery for coming decades and can prove to be a better alternative for conventional dosage forms in the future.

\section{ABBREVIATIONS}

$\mathrm{API}=$ active pharmaceutical ingredient, $\mathrm{BCS}=$ biopharmaceutical classification system, $\mathrm{CAGR}=$ compound annual growth rate, $\mathrm{CDER}=$ Center for Drug Evaluation and Research, EPO= European patent office, $\mathrm{FDandC}=$ food, drug, and cosmetic, IPO= Indian Patent Office, HME $=$ hot melt extrusion, USPTO $=$ United States Patent and Trademark Office.

\section{AUTHORS CONTRIBUTIONS}

All the authors have contributed equally

\section{CONFLICT OF INTERESTS}

Declared none

\section{REFERENCES}

1. Bala R, Pawar P, Khanna S, Arora S. Orally dissolving strips: a new approach to oral drug delivery system. Int J Pharm Investig 2013;3:67-76.

2. Siddiqui MN, Garg G, Sharma PK. A short review on a novel approach in oral fast dissolving drug delivery system and their patents. Adv Biol Res 2011;5:291-303.

3. Patil SL, Mahaparale PL, Tiwari S, Pavour KV, Sane PN. Fast dissolving oral films: an innovative drug delivery system. Int J Res Rev Pharm Appl Sci 2012;2:482-96.

4. Patel D, Patel M, Upadhyay P, Shah N, Shah S. A review on mouth dissolving film. J Pharm Sci Biosci Res 2015;5:266-73.

5. Radhakisan UR, Chavan V, Tribhuvan N. Mouth dissolving film and their patent: an overview. Asian J Biomed Pharm Sci 2012;3:39-42.

6. Mandeep K, Rana AC, Nimrata S. Fast dissolving films: an innovative drug delivery system. Int J Pharm Res Allid Sci 2013;2:14-24.

7. Rathborne N, Hadgraft J, Roberts M. Oral thin films, in orally disintegrating tablet and film technologies. Technol Catalyst Int Corporation 2006;4:18-31.

8. Khatoon N, Rao NR, Reddy BM. Overview on fast dissolving oral films. Int J Chem Pharm Sci 2013;1:63-75.

9. Patil P, Shrivastava S. Fast dissolving oral films: an innovative drug delivery system. Int J Sci Res 2014;3:2088-93.
10. Hariharan, Madhu, Bogue, B Arlie. Orally dissolving film strips (ODFS): the final evolution of orally dissolving dosage forms. drug delivery technology, Montville. New Jersey 2009;9:24-9.

11. Aggarwal J, Singh G, Saini S, Rana AC. Fast dissolving films: a novel approach to oral drug delivery. Int Res J Pharm 2011;2:69-71.

12. Mahajan A, Chabra N, Aggarwal G. Formulation and characterization of fast dissolving buccal films: a review. Pharm Lett 2011;3:152-65.

13. Prakruti $M$, Gangurde $A B$, Pranali V. Oral film technology: challenges and future scope for the pharmaceutical industry. Int J Pharmacogn Phytochem Res 2015;3:183-203.

14. Panda BP, Dey NS, Rao ME. Development of innovative orally fast disintegrating film dosage forms: a review. Int J Pharm Sci Nanotech 2012;5:1666-74.

15. Rathi V, Senthil V, Kammili L, Hans R. A Brief review on oral film technology. Int J Res Ayurveda Pharm 2011;2:1138-47.

16. RP Dixit, SP Puthil. Oral strip technology: overview and future potential. J Controlled Release 2009;139:94-107.

17. Nagar P, Chauhan I, Yasir M. Insights into polymers: film formers in mouth dissolving films. Drug Invention Today 2011;3:280-9.

18. Dey P, Gosh A. Wafers: an innovative advancement of orodispersible films. Int J Appl Pharm 2016;8:1-7.

19. Reza KH, Chakraborthy P. Recent industrial development in oral thin film technology: an overview. Pharma Tutor 2016;4:17-22.

20. Sloboda M, Bharnatt S. Formulation flexibility broadens the scope for oral thin film technology. Adhesives Res 2011;5:22-4.

21. Sharma D, Kaur D, Verma S, Singh D, Singh M, Singh G, et al. Fast dissolving oral films technology: a recent trend for an innovative oral drug delivery system. Int J Drug Delivery 2015;7:60-75.

22. Heer D, Aggarwal G, Hari Kumar SI. Recent trends of fast dissolving drug delivery system-an overview of formulation technology. Pharmacophore 2013;4:1-9.

23. Keshari ADr, Sharma P, Parveez N. Fast dissolving oral films: a novel and innovative drug delivery system. Int J Pharm Sci Res 2014:5:92-5.

24. Arya A, Chandra A, Sharma V, Pathak K. Fast dissolving oral films: an innovative drug delivery system and dosage form. Int J Chem Tech Res 2010;2:576-83.

25. Liang CA, Chen HL. Fast dissolving intraoral drug delivery systems. Expert Opin Ther Patents 2001;11:981-6.

26. Parmar D, Patel U. Orally fast dissolving film as dominant dosage for quick releases. Int J Pharm Res Biosci 2012;1:24-41.

27. Karki S, Kim H, Na SJ, Shin D, Jo K, Lee J. Thin films as an emerging platform for drug delivery. Asian J Pharm Sci 2016;11:559-74

28. Joshua J, Hari R, Jyothish F, Surendran S. Fast dissolving oral thin films: an emerging dosage form for quick release. Int J Pharm Sci Rev Res 2016;38:282-9.

29. Bhyan B, Jangra S, Kaur M, Singh H. Orally fast dissolving films: innovations in formulation and technology. Int J Pharm Sci Rev Res 2011;9:9-15.

30. Pandya K, Patel K, Patel M, Patel N. Fast dissolving films: a novel approach to oral drug delivery. Asian J Pharm Sci 2013;3:25-31.

31. www.researchandmarkets.com/research/ckvqw7/oral\%20thi $\mathrm{n} \% 20$ film. [Last accessed on 20 Jun 2018]

32. www.transparencymarketsearch.com/thin-film-drugmanufacturing-market. [Last accessed on 20 Jun 2018]

33. Thakur N, Bansal M, Sharma N, Yadav G, Khare P. Overview a novel approach of fast dissolving films and their patents. Advan Biol Res 2013;7:50-8. 